\title{
A Geospatial Agent-Based Model of the Spatial Dispersal of Albanian Immigrant Population in Canada
}

\author{
Leogena Zhaka (Corresponding author) \\ Faculty of Computer Science, University of Tirana \\ Bulevardi Zogu I, Tirane, Albania \\ E-mail: leogena.zhaka@fshn.edu.al \\ Endrit Xhina \\ Faculty of Computer Science, University of Tirana \\ Bulevardi Zogu I, Tirane, Albania \\ E-mail: endri.xhina@fshn.edua.al
}

\begin{abstract}
International migration is a well-known phenomenon all over the world. Albania, a small country on Southeastern Europe's Balkan Peninsula, has been no exception to experiencing both emigration and immigration. Based on information gathered form INSTAT, Institute of Statistics Albania, migration has been observed to have far larger numbers than immigration for this country, based on information gathered since the year 1990 when the transition from communist regime to a democratic country began. One of the countries where Albanians have immigrated and settled with their families is Canada. The focus of this study is to research, develop and implement a geospatial agent-based model to simulate the process of settling in a new location for Albanian immigrants in Canada. Data gathered is based on Canadian Census for households and languages spoken at home particularly Albanian language. This model is implemented using NetLogo with real geospatial datasets. The proposed model has the potential to be used as part of the planning process by the Albanian State Minister for Diaspora, whose mission is to promote and strengthen the overall cooperation between the Albanian communities living outside of the Republic of Albania and the host countries, in every aspect.
\end{abstract}

Keywords: Geospatial, Agent-based model, Immigration, Albanians, Canada.

DOI: $10.7176 / \mathrm{JSTR} / 7-07-01$

\section{Introduction}

It is a well-known phenomenon that many residents of the second world countries [1] have left their countries in search of better opportunities in the first world countries [1]. Albania, a country on the Balkan Peninsula in southeastern Europe, as part of this category was no different than other second world countries related to the massive emigration.

\subsection{Albanian Emigration}

Albania was the poorest country of Europe when the communism regime was demised from the country in 1990 . In the following years an estimate of $15-20 \%$ of the residents left the country due to the difficult economical and political situation and the removal of the isolation law [2][3].

1997 was another year with a high number of emigrants for Albania due to the collapse of the pyramidal scheme companies that left many in a devastating situation with no means of supporting themselves and their families [4].

Albanian emigration changed from illegal to legal and many skilled workers have left the country since 2010 due to the first world countries immigration policies changes [4][5]. (Table 1 showing numbers for Albanian migration).

1 | $\mathrm{P}$ a g e

www.iiste.org 
Table 1. Number of emigrations, immigration, and net migration, 2014-2019

\begin{tabular}{|c|c|c|c|}
\hline Years & Emigration & Immigration & Net Migration \\
\hline 2014 & 46,525 & 24,740 & $-21,785$ \\
\hline 2015 & 41,443 & 20,843 & $-20,600$ \\
\hline 2016 & 32,532 & 23,060 & $-9,473$ \\
\hline 2017 & 39,905 & 25,003 & $-14,902$ \\
\hline 2018 & 38,703 & 23,673 & $-15,030$ \\
\hline 2019 & 43,835 & 20,753 & $-23,082$ \\
\hline
\end{tabular}

The data in the table above are available from The Institute of Statistics (INSTAT) Website, Albania (http://www.instat.gov.al).

\subsection{Immigration in Canada}

Canada is otherwise known as the Land of Immigrants due to welcoming millions of newcomers in the last 200 years [6]. It is a first world country part of the G7 (an inter-governmental political forum) [7], with two official languages, English and French, and a Constitution that has Multiculturalism, as part of the "Canadian Charter of Rights and Freedoms" that indicates that Canadians celebrate, and respect one another, and together live in harmony [6].

\subsection{Albanians in Canada}

Canada with its powerful political and economical presence has been one of the preferred choices for the Albanian immigrants. Many have applied to become Canadian permanent residents since the 1990s when the isolation policy was lifted for Albanians. Since 2015 that Canada has introduced a new immigration policy called Express Entry [8] there has been an increase in the number of Albanian newcomers in Canada, and they have settled in different provinces around the country [9][10].

\subsection{Choice of Province for Albanian newcomers}

In this article we will at first focus on Albanian speaking households and their geographic distribution among the Canadian Provinces based on the 2011 census data. Then we will describe a prototype agent-based model project, build in NetLogo [11] using the GIS extension [12], that was used to examine a newcomer's choice of Province for settlement based on a set of rules for the agents that will represent the Albanian newcomers. Then we will discuss the findings after the comparison between the results of our prototype and the data related to Albanian households on the 2016 census data.

\section{Methodology}

Our focus is to create an agent-based model that allows experimenting and testing the behaviour of Albanian newcomers to Canada related to their choice of residency.

\subsection{Study Area}

Canada is located in the North America continent with 3 frontiers being oceans, Atlantic, Pacific, and Arctic, and one being the USA. The country includes five distinct regions: The Atlantic Provinces, Central Canada, The Prairie Provinces, The West Coast, The Northern Territories [13] [14].

The National Capital is Ottawa, chosen as the capital in 1857, located on the Ottawa River [14]. Canada has ten provinces and three territories, where reside about 34 million people. Each province and territory has its own capital city. Most of the Canadian population lives in the city, while the rest have chosen to live in small towns, rural areas and in other areas in between [13] [14].

\subsection{Datasets}

In order to simulate the Albanian newcomer immigrant spatial dynamics for the choice of residency location in Canada, information about Albanian household distribution among provinces and territories was gathered from Statistics Canada [9][10]. This information was compiled in a table representing the number of the households where Albanian language was spoken across Canada (Table 2).

2 I P a g e

www.iiste.org 
Table 2. Number of Households where Albanian language is spoken

\begin{tabular}{|l|c|c|}
\hline Province or Territory & Census 2011 & Census 2016 \\
\hline Newfoundland and Labrador / Terre-Neuve-et-Labrador & 100 & 90 \\
\hline Prince Edward Island / Île-du-Prince-Édouard & 105 & 100 \\
\hline Nova Scotia / Nouvelle-Écosse & 270 & 305 \\
\hline New Brunswick / Nouveau-Brunswick & 15 & 50 \\
\hline Quebec / Québec & 2,540 & 2,960 \\
\hline Ontario & 18,275 & 20,120 \\
\hline Manitoba & 330 & 385 \\
\hline Saskatchewan & 180 & 430 \\
\hline Alberta & 1,775 & 2,395 \\
\hline British Columbia / Colombie-Britannique & 1,410 & 1,545 \\
\hline Yukon & 0 & 10 \\
\hline Northwest Territories / Territoires du Nord-Ouest & 10 & 10 \\
\hline Nunavut & 0 & 0 \\
\hline
\end{tabular}

The data in the table above are available from the Statistics Canada Website, Census 2011, and Census 2016 (https://www.statcan.gc.ca/eng/start).

A shapefile map that includes information dataset related to Canada's provinces and territories was found on Statistics Canada website [15].

\subsection{Agent-based Model}

In this study, we are proposing a model that was built to realistically represent the residence selection behaviour of Albanian newcomer immigrants arriving to a Canada, and the emerging patterns of spatial distribution in the country. Immigrants' choice of the residential location is influenced by the presence of family, friends, and other people of the same nationality. One element that will influence their decision is their expectations related to jobs, the economic status, and wellbeing for the future.

For the proposed model, Canada and its provinces and territories acted as the world or environment, while Albanian immigrants were considered as agents, and their decision process to select a place to live was simulated by a set of rules to follow to reach a decision for a location.

Firstly, agents in red, person shape, representing existing Albanian households were added in each province corresponding the values on Table 2, column Census 2011. Then the newcomers were added in green person shape as free agents. Attributes such as place distance sensitivity from Albania, expectations, level of indecisiveness were used in the decision-making process of the agents.

The rules set for the agents representing newcomers were:

a. Albanian immigrant agents will move to areas where other expats are present. (When the immigrant arrives, the province selection begins, and the location is considered favourable if there are already Albanian immigrants in the province.)

b. Albanian immigrants prefer to be in provinces that offer shorter distance flight options to Albania. (Immigrants leave their old life including friends and family when move out of the country, understandably they prefer to settle in areas where they have a possibility to take a flight back to Albania to visit from time to time. In our model the less flight hours to reach Albania that a province offers the better is for a newcomer.)

c. The economic situation of a province will influence the decision of the agents (Immigrant agents are most likely to locate in areas with higher job opportunities.)

d. The marital status of an immigrant will increase the percentage of the decision to be random (Single immigrants tend to take more risk and thus are more open to relocate to areas not explored yet by their known expats. On the other hand, immigrants with kids, especially

3| P a g e

www.iiste.org 
infants tend to prefer to stay closer to the expat community as they need more help to integrate their entire family in the new environment.)

Once all the rules are evaluated, the agent will move to the province of their choice and will appear on a random point inside the province polygon that the agent chose in a green person shape.

extensions [ gis ] ; the gis extension allows us to read standard GIS data
breed [ immigrants immigrant]
breed [ province-labels province-label ] immigrants are the ones purchasing tickets

Figure 1: GIS extension and immigrant agents specified in the model project

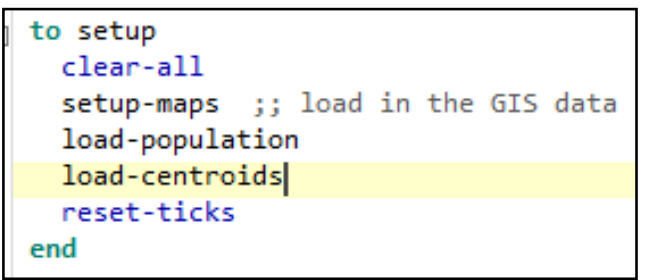

Figure 2: Setup method. Called on click of the setup button. The functions to setup the maps, load Albanian immigrants on each province or territory, load the names of the provinces on the centroids of the province polygons are called respectively

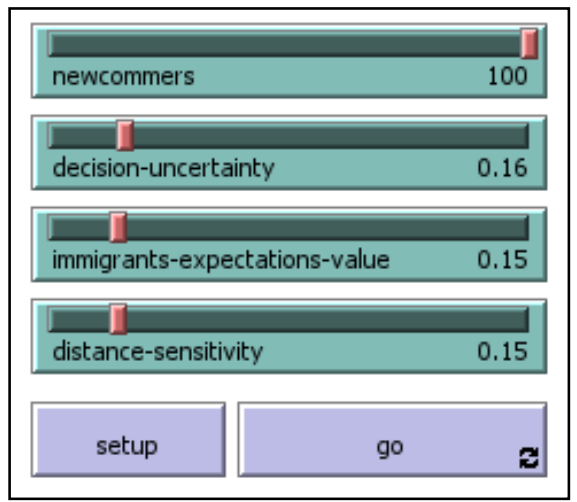

Figure 3: Existing Albanian households represented as agents in each province

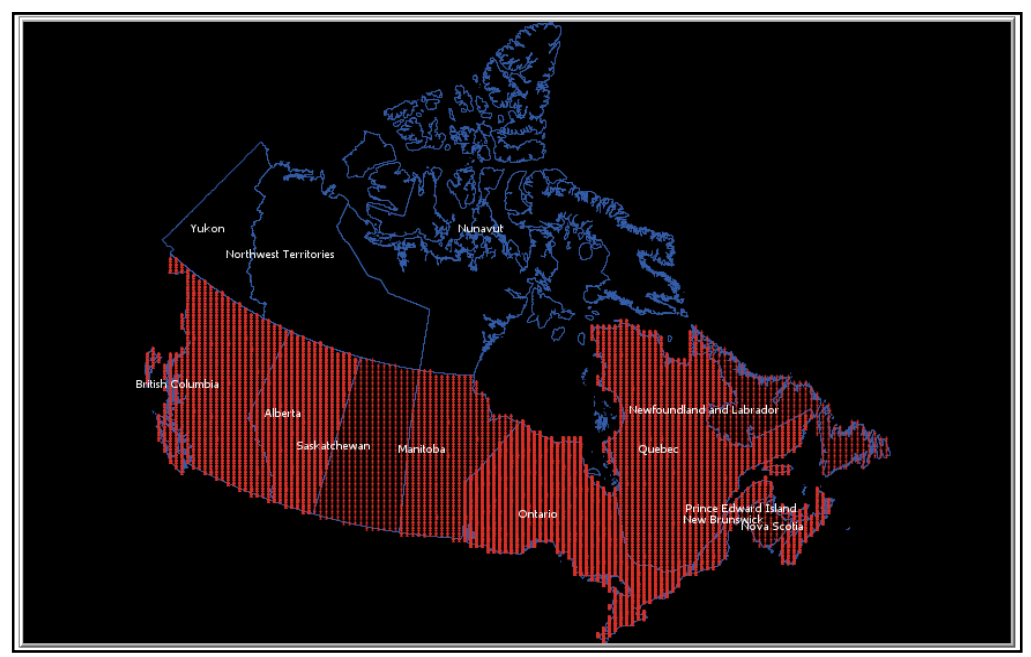

Figure 4: NetLogo sliders and buttons interface 


\section{Results}

Several tests were conducted, using 4 variation variables, as shown in Figure 4, the first one represents the number of newcomers that the simulation is ran with, the second the level of uncertainty that the agent tolerates, the level that the expectations that the newcomer has affect the decision, the sensitivity level that the agent has towards the distance between Albania and the province.

The preferred provinces for settlement were Ontario followed by Quebec. After a series of number combinations of the variables, 20 test cases were run for each combination. The average of the results was calculated and the resulted numbers per province were compared with those of the Census 2016 for the households were Albanian was used. The numbers were similar with most of the difference being the Territories (Table 3). For more accurate results the model can be improved by taking into consideration the internal migration of Albanians in Canada, different incentives and immigration strategies and policies that different provinces have implemented and the newcomers' financial status before immigration.

Table 3. Test results for number of Households where Albanian language is spoken

\begin{tabular}{|l|c|}
\hline Province or Territory & Results \\
\hline Newfoundland and Labrador / Terre-Neuve-et-Labrador & 102 \\
\hline Prince Edward Island / Île-du-Prince-Édouard & 110 \\
\hline Nova Scotia / Nouvelle-Écosse & 297 \\
\hline New Brunswick / Nouveau-Brunswick & 23 \\
\hline Quebec / Québec & 3,071 \\
\hline Ontario & 20,808 \\
\hline Manitoba & 369 \\
\hline Saskatchewan & 230 \\
\hline Alberta & 1,884 \\
\hline British Columbia / Colombie-Britannique & 1,496 \\
\hline Yukon & 0 \\
\hline Northwest Territories / Territoires du Nord-Ouest & 10 \\
\hline Nunavut & 0 \\
\hline
\end{tabular}

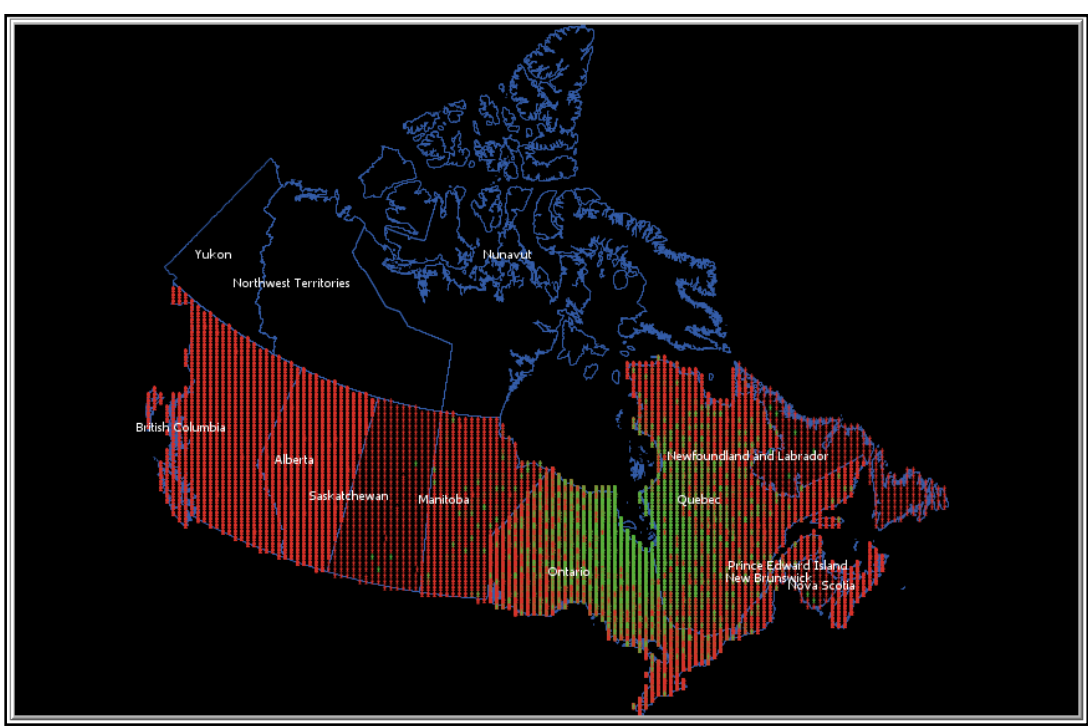

Figure 5: Newcomer immigrant agents represented by green person shapefile

5 | P a g e

www.iiste.org 


\section{Conclusions}

In this study, we created an agent-based model project, by using NetLogo and its GIS extension, a vector dataset map of Canada and Canadian Census datasets of households where Albanian is used as a language. This environment was used to visualize the distribution of Albanian immigrants in each province based on the Census 2011 dataset and analyze the spatial decisions for settlement of the agents representing Albanian newcomer immigrants in Canada. To do so, multiple variables were considered in the formulation of the model. The resulted data were compared with the data related to Albanian households on the 2016 census data. The resulted numbers were similar to those of the census.

This research a new contribution to the research of agent-based modeling for the immigration of Albanians to Canada. This model can be ameliorated and turned into a decision platform that would be of assistance in the planning of events and projects by the Albanian State Minister for Diaspora that is responsible for aiding Albanians living outside of Albania to have access to means that help them maintain their culture and tradition while embracing the culture of the country they live in [16].

\section{Acknowledgements}

The authors would like to thank Mr Erni PAPAKRONI for their technical assistance in the software research phase of this article.

\section{References}

[1] Nations Online: First, Second and Third World, https://www.nationsonline. org/oneworld /third_world_countries.htm

[2] Konica, Nevila \& Filer, Randall \& studium, Univerzita. (2009). Albanian Emigration; Causes and Consequences. South-Eastern Europe Journal of Economics. 1.

[3] IMF. (1997) Albania: Recent Economic Developments," Washington D.C.: International Monetary Fund. February 20, 1997

[4] Kosta Barjaba, Joniada Barjaba (2015) Embracing Emigration: The Migration-Development Nexus in Albania The online journal of the migration policy institute, https:/www.migration policy. org/article/embracing-emigration-migration-development-nexus-albania\#: : $\quad$ text= The $\% 202008 \% 20$ financial $\% 20$ crisis $\% 20$ derailed,destinations $\%$ E2\%80\%94were $\% 20$ particularl y\%20hard\%20hit.

[5] Instat, Institute of Statistics Albania. In: Migration and migrant integration, http://www.instat. gov.al/al/temat/treguesit-demografik $\% \mathrm{C} 3 \% \mathrm{AB}$-dhe-social $\% \mathrm{C} 3 \% \mathrm{AB} / \mathrm{migracioni}$-dhe-integrimii-migrant $\% \mathrm{C} 3 \% \mathrm{ABve} / \#$ tab3

[6] Government of Canada, Discover Canada: Who We Are, https://www.canada.ca/en/immigrationrefugees-citizenship/corporate/publications-manuals/discover-canada/read-online/who-arecanadians.html

[7] Government of Canada, International Relations: Canada and the G7, https:/www.interna tional.gc.ca/world-monde/international_relations- relations_ internationales/g7/ index.aspx? lang= eng

[8] Government of Canada, Immigrate through Express Entry, https://www.canada. ca/en /immigration-refugees-citizenship/services/immigrate-canada/express-entry.html 
[9] Statistics Canada. Census Profile, 2016 Census. In: Census Profile [Internet]. Language Spoken at Home (263), Single and Multiple Responses of Language Spoken at Home (3), Mother Tongue (269) and Age (7) for the Population Excluding Institutional Residents of Canada, Provinces and Territories, Census Metropolitan Areas and Census Agglomerations, 2016 Census - 100\% Data, https://www12.statcan.gc.ca/census-recensement/2016/dp-pd/dt-td/Rp-eng.cfm? $\mathrm{LANG}=\mathrm{E} \& \mathrm{APATH}=3 \& \mathrm{DETAIL}=0 \& \mathrm{DIM}=0 \& \mathrm{FL}=\mathrm{A} \& \mathrm{FREE}=0 \& \mathrm{GC}=0 \& \mathrm{GID}=0 \& \mathrm{GK}=0 \& \mathrm{GRP}$ $=1 \& \mathrm{PID}=110212 \& \mathrm{PRID}=10 \& \mathrm{PTYPE}=109445 \& \mathrm{~S}=0 \& \mathrm{SHOWALL}=0 \& \mathrm{SUB}=0 \&$ Temporal $=201$ $6 \& \mathrm{THEME}=118 \& \mathrm{VID}=0 \& \mathrm{VNAMEE}=\& \mathrm{VNAMEF}=$

[10] Statistics Canada. Census Profile, 2011 Census. In: Census Profile [Internet]. Detailed Mother Tongue (192), Single and Multiple Language Responses (3), Age Groups (7) and Sex (3) for the Population Excluding Institutional Residents of Canada, Provinces, Territories, Census Divisions and Census Subdivisions, 2011 Census, https://www12.statcan.gc.ca/censusrecensement $/ 2011 / \mathrm{dp}$-pd/tbt-tt/Rp-eng.cfm?LANG=E\&APATH=3\&DETAIL $=0 \& D I M=0 \& F L=$ $\mathrm{A} \& \mathrm{FREE}=0 \& \mathrm{GC}=0 \& \mathrm{GID}=0 \& \mathrm{GK}=0 \& \mathrm{GRP}=1 \& \mathrm{PID}=103251 \& \mathrm{PRID}=10 \& \mathrm{PTYPE}=101955 \& \mathrm{~S}$ $=0 \&$ SHOWALL $=0 \& \mathrm{SUB}=0 \&$ Temporal $=2011 \& \mathrm{THEME}=90 \& \mathrm{VID}=0 \& \mathrm{VNAMEE}=\& \mathrm{VNAMEF}$ $=$

[11] NetLogo https://ccl.northwestern.edu/netlogo/

[12] NetLogo GIS Extension https://ccl.northwestern.edu/netlogo/6.0.1/docs/gis.html

[13] Michael Broadway (2015) The Geographies of Canada, The AAG Review of Books, 3:4, 190192

[14] Government of Canada, Discover Canada: Canada's Regions, https://www.canada.ca/ en/immigration-refugees-citizenship/corporate/publications-manuals/discover-canada/readonline/canadas-regions.html

[15] Statistics Canada: Census Program, Alternative format, https://www12.statcan.gc.ca/censusrecensement/alternative_alternatif.cfm? $1=$ eng\&dispext=zip\&teng $=1 p r \_000 \mathrm{~b} 16 \mathrm{a} \_$e.zip\&k=\%20\% 20\%20\%2027960\&loc=http://www12.statcan.gc.ca/census-recensement/2011/geo/boundlimit/files-fichiers/2016/lpr_000b16a_e.zip

[16] State Minister for Diaspora. In: Mission, https://diaspora.gov.al/en/misioni/ 